\title{
A BRIEF METHOD FOR THE SYNTHESIS AND \\ CHARACTERIZATION OF A HYBRID MATERIAL BASED ON CARBON NANOTUBES AND ALUMINA
}

\author{
MÉTODO BREVE PARA LA SÍNTESIS Y CARACTERIZACIÓN DE UN MATERIAL \\ HÍBRIDO A BASE DE NANOTUBOS DE CARBONO Y ALUMINA
}

\author{
Oscar Corona $^{(1,2)}$; Franklin J. Méndez ${ }^{(2,3)}$ \\ (1) Instituto Superior de Formación Docente Salomé Ureña - ISFODOSU. República Dominicana. \\ (2) Instituto Venezolano de Investigaciones Cientificas - IVIC. República Bolivariana de Venezuela. \\ (3) Universidad Nacional Autónoma de México - UNAM, México. \\ Email: oscar.corona@isfodosu.edu.do \\ https://doi.org/10.33789/talentos.7.2.138
}

\begin{abstract}
This research is presented in the area of composite materials; whose matrix is alumina with carbon nanotubes. The synthesis of CNT-based materials in alumina is driven by the exceptional chemical and mechanical properties of both materials. For this proposal, critical aspects such as the processing technique, the interfacial mechanisms between the $\mathrm{Al}_{2} \mathrm{O}_{3}$ matrix and CNTs were revised, without losing the focus on the application of this composite in the structural area and determining the strengthening of the matrix due to the presence of reinforcements. This study deals with the synthesis and characterization of a hybrid material based on multi-walled carbon nanotubes (CNTs) and alumina. A simple and efficient methodology is proposed, in which the composite material CNTs/alumina is prepared from the combination of nanofilaments with an aluminum-rich material. Characterization by MET gave evidence of typical carbon nanotube structures supported on aluminous material. Furthermore, MEB-EDS analysis of hybrid composite material confirmed the presence of carbon nanofilaments embedded in the alumina matrix. This study as an initial phase of the research allowed to identify a simple and novel methodology that will be extended in characterization and determination of structural relationships with processing parameters, and it is considering to perform multiscale modeling to know the mechanisms inherent in the compatibility between the matrix and nanofilaments, and thus the phenomenon of reinforcement.
\end{abstract}

Keywords: Carbon nanotubes; alumina; hybrid-composite material; calcination synthesis.

Recibido: 17 de julio de 2020

Aceptado: 19 de octubre de 2020

Publicado como artículo científico en la Revista de Investigación Talentos VII (2), 84-90 
Resumen: Esta investigación se presenta en el área de materiales compuestos, cuya matriz es alúmina con nanotubos de carbono. La síntesis de materiales basados en CNT y alúmina está impulsada por las excepcionales propiedades químicas y mecánicas de ambos materiales. Para esta propuesta se revisaron aspectos críticos como la técnica de procesamiento, los mecanismos interfaciales entre la matriz de $\mathrm{Al}_{2} \mathrm{O}_{3}$ y los CNT, sin perder el foco en la aplicación de este compuesto en el área estructural, y determinando el fortalecimiento de la matriz por la presencia de refuerzos. Este estudio se ocupa de la síntesis y caracterización de un material híbrido basado en nanotubos de carbono de paredes múltiples (CNT) y alúmina. Se propone una metodología sencilla y eficaz, en la que el material compuesto CNTs/alúmina se preparó a partir de la combinación de nanofilamentos con un material rico en aluminio. La caracterización por MET dio evidencia de estructuras típicas de nanotubos de carbono soportadas sobre material aluminoso. Además, el análisis MEB-EDS de material compuesto híbrido confirmó la presencia de nanofilamentos de carbono incrustados en la matriz de alúmina. Este estudio como fase inicial de la investigación permitió identificar una metodología simple y novedosa que se extenderá en la caracterización y determinación de las relaciones estructurales con los parámetros de procesamiento, y se está considerando realizar un modelado multiescalar para conocer los mecanismos inherentes a la compatibilidad entre la matriz y nanofilamentos, y por tanto el fenómeno de refuerzo.

Palabras clave: Nanotubos de carbono; alúmina; material compuesto híbrido; síntesis por calcinación.

\section{INTRODUCTION}

Advanced ceramic materials such as alumina $\left(\mathrm{Al}_{2} \mathrm{O}_{3}\right)$, manufactured by conventional technologies have high rigidity, high toughness, excellent thermal stability and relatively low density. However, the extreme brittleness of some nanocrystalline ceramics have limited their potential use in many engineering applications (Ovid'Ko \& Sheinerman, 2010) Currently, there is growing interest in the study and preparation of ceramic nanocomposite matrices reinforced with both single and multi-walled carbon nanotubes (CNTs), mainly for structural applications. In many researchs, have been recognized the great potential of both carbon nanotubes and nanoalumina in terms of their mechanical properties (Sun et al., 2005).
Two nanomaterials has been managed to manufacture hybrid materials, which have been very interesting in many applications between nanofluids, nanocomposite ceramics based on alumina and nanotubes, alloys reinforced with nanotubes, among others (Michálek, 2014). There is a trend, which is focused on the preparation of materials that could be used as additive for oil well cements, i.e. carbon nanotubes and alumina. In this sense, it has been widely reported the advantages that both nanomaterials separately provide to cementitious systems, in terms of their most outstanding mechanical properties, such as compressive strength, tensile strength, ductility, thermal stability and crack propagation (Nazari \& Riahi, 2011; 
Ferro, 2016). For the preparation of this type of hybrid materials some authors have proposed the growth of carbon nanotubes by using traditional methods of synthesis, i.e. chemical vapour deposition (CVD), from beds of nanometric alumina doped with catalysts, obtaining nanotube hybrid material within alumina matrices. Others have proposed the use of a precursor for synthesis of aluminas (aluminium hydroxides or oxyhydroxides) combined with functionalized carbon nanotubes, prepared by plasma sintering, and thus achieving hybrid materials [3]. The main goal of this research is the use of an original method to synthesize a hybrid material based on nanotubes and alumina through an industrial by-product with potential engineering applications.

\section{MATERIALS AND METHODS}

For this study multi-walled carbon nanotubes (CNTs) produced by CVD were used as received (Graphistrength $\AA$ from ARKEMA, Purity 90-97\%, average number of walls: 5-15, diameter: $10-15 \mathrm{~nm}$, length: 0.1-10 $\mu \mathrm{m}$ and specific gravity of 2 ).

Gibbsite was an industrial by-product from the aluminium production at CVG-Bauxilum, C.A, Venezuela.

Reagent-grade commercial products were used without further purification. Nitric acid, citric acid and methanol were provided by FLUKA, VENEQUIM and MERCK, respectively.

The synthesis method was based on the preparation of a saturated solution of aluminum nitrate, which was obtained by acidic digestion of an industrial byproduct (Gibbsite) using $6 \mathrm{M} \mathrm{HNO}_{3}$ and reflux conditions for 12 hours. The enriched aluminum solution was mixed with citric acid as template up to its complete dissolution, then the admixture was placed on a hot plate at $350^{\circ} \mathrm{C}$ for 8 hours, after water evaporation, an ochre/brown solid (SP) was obtained, and typically composed by aluminum hydroxide and oxyhydroxides (Xu et al., 2013). CNTs:SP admixture at 1:10 ratio was suspended in methanol and a Branson ultrasonic tip was used for its homogeneous dispersion and distribution (Cheng, 2017). Methanol was completely evaporated $\left(80^{\circ} \mathrm{C}\right.$ overnight $)$ and the resulting solid (CNTs/SP) was calcined at $800{ }^{\circ} \mathrm{C}$ in a tubular furnace and quartz reactor for 12 hours under anoxic conditions (argon flow; $5 \mathrm{ml} / \mathrm{min}$.). Electron microscopy was performed in order to know the morphology and composition of materials.

\section{RESULTS AND DISCUSSION}

Characterization of CNT/SP admixture by transmission electron microscopy (TEM) revealed the presence of structures with characteristic morphologies of carbon nanotubes, 10-walled CNTs, mainly onion array with interlaminar distances around $3.65 \AA$, and supported on aluminous matrix as shown in TEM micrograph in Figure 1 (Salama et al., 2017)

Figure 2 shows carbon nanotube embedded in alumina matrix, which is confirmed by energy dispersive spectrum analysis given in Figure 3, where is shown the presence of $\mathrm{C}$, $\mathrm{Al}$, and $\mathrm{O}$ as major elements in the sample and their composition is summarized in Table I. 

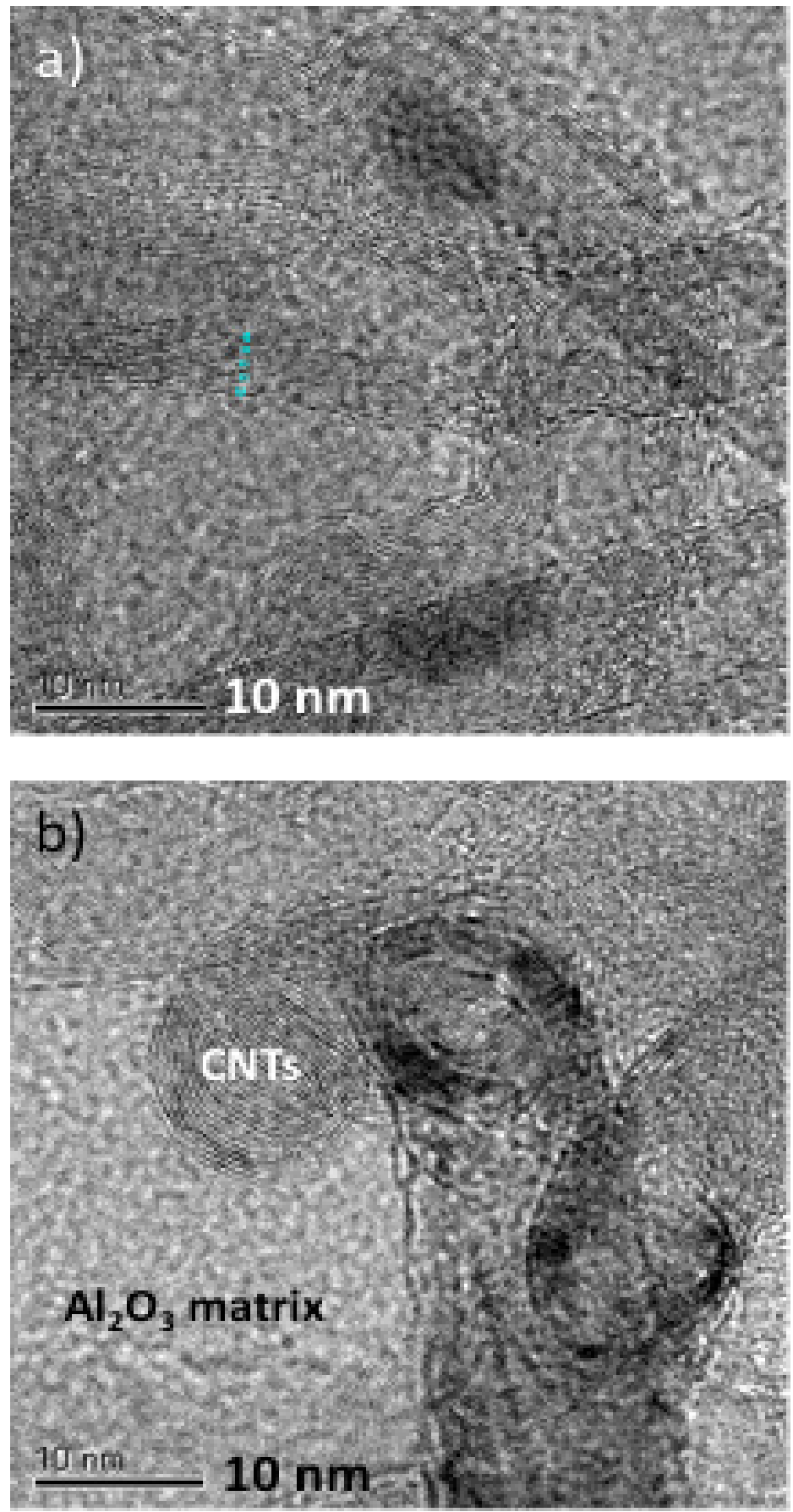

Fig. 1. TEM image of multi-walled carbon nanotubes on the aluminum-based matrix (CNT/SP) a) 10-walled CNTs and b) Onion arrangement of CNTs embedded in the alumina matrix.

Table I. EDS compositional analysis of hybrid composite.

\begin{tabular}{llll}
\hline Element & \% Mass & \% Atomic & Total \\
\hline C K & 64.56 & 71.73 & 42.17 \\
O K & 31.62 & 26.37 & 14.22 \\
Al K & 3.83 & 1.89 & 21.46 \\
\hline
\end{tabular}

Fuente: Los autores de la investigación 


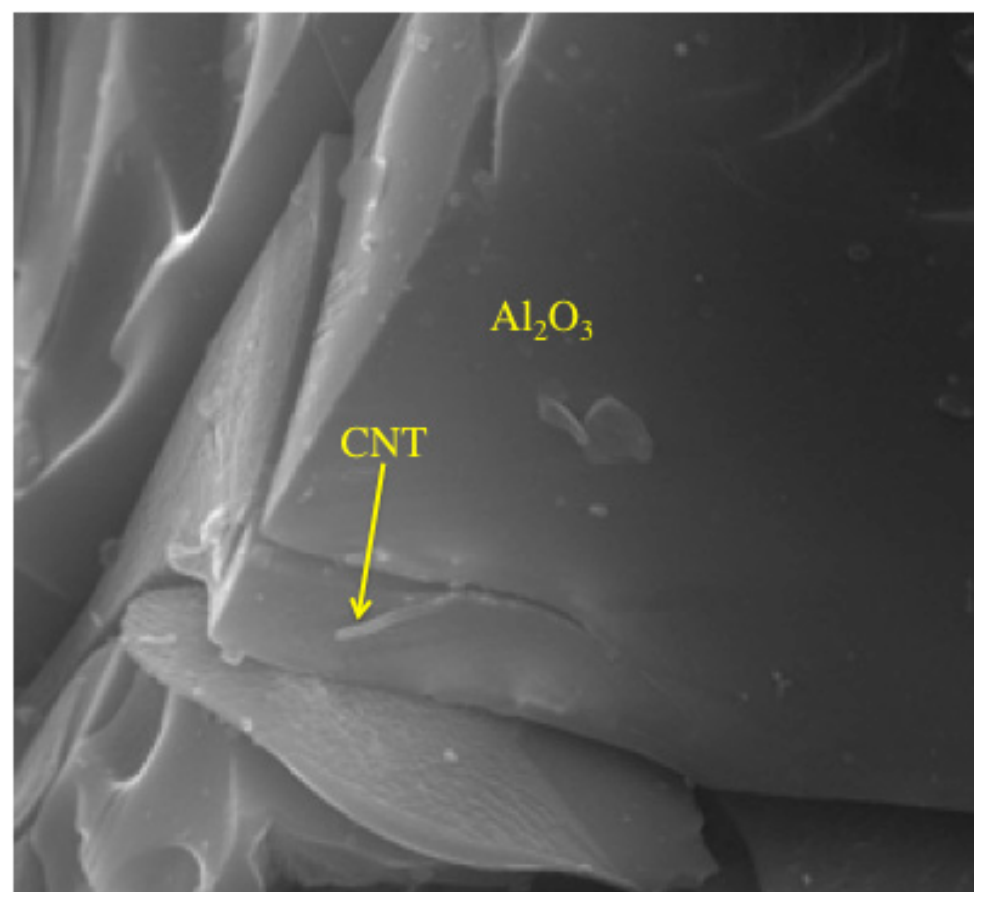

Fig. 2. SEM image of carbon nanotubes embedded within alumina (hybrid nanocomposite).

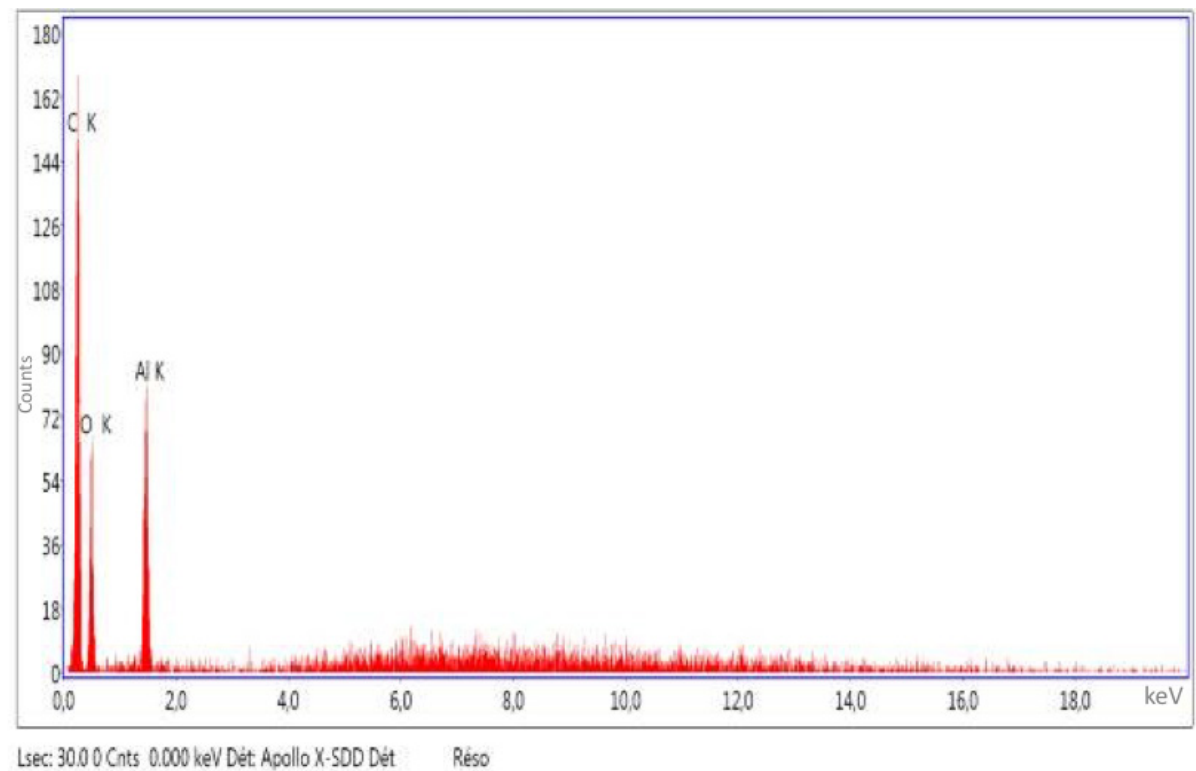

Fig. 3. EDS analysis of hybrid nanocomposite.

The synthesis method developed contrasts with reported techniques, e.g. electrodeposition, in situ growth of nanotubes, solid synthesis by mechanical methods, among others. (Mohammed \& Chen, 2019). In this research, a one-pot synthesis was carried out with the use of a starting material that is an industrial by-product. The most usual methodology of synthesis for this kind of composite material is the ball-milling process, this is efficient to achieve homogeneous particle sizes but also promotes agglomeration ofCNTs in the matrix. Additionally, many of the synthesis methods cause damages to CNTs due to mechanical, thermal or chemical conditions (Salama et al., 2017). In this study, the decomposition or 
transformation temperatures of CNTs were taken into consideration and therefore 800 ${ }^{\circ} \mathrm{C}$ was established as working temperature, a temperature at which the transformation of the starting aluminous material into $\mathrm{Al}_{2} \mathrm{O}_{3}$ was guaranteed, without affecting the structural characteristics of the CNTs.

\section{CONCLUSIONS}

An efficient and clean method for the synthesis of a hybrid material constituted by alumina and carbon nanotubes has been presented. Results suggest that all the aluminous material was completely transformed into aluminum oxide and carbon nanofilaments kept their composition and morphology after thermal treatment at $800{ }^{\circ} \mathrm{C}$. The composite synthetized has potential to be used in structural applications as reinforcement and isolator, based on the synergy of both materials. On the base of findings, future research could be suggested, including the relationships between the synthesis parameters and micro- and nanostructures, and multiscale mechanical modeling and simulation, to know the mechanisms inherent in the compatibility between the matrix and nanofilaments, and thus the phenomenon of reinforcement for critical engineering applications.

\section{ACKNOWLEDGEMENT}

The authors want to thank PDVSA Intevep for financial support, to the Surface Physical Chemistry Laboratory (IVIC) and Material Engineering and Nanotechnology Laboratory (IVIC) for their technical collaboration.

\section{REFERENCES}

Cheng, C. B., Fan, R. H., Qian, L., Wang, Z. Y., Xie, P. T., Dong, L. H., \& Yin, Y. S. (2017). Multi-Walled Carbon Nanotube-Alumina Nanocomposites with Dielectric Resonance-Induced Negative Permittivity Behavior. Materials Science Forum, 898, 1764 1769. https://doi.org/10.4028/www.scientific. net/msf.898.1764

Ferro, G., Tulliani, J.-M., \& Musso, S. (2016). Carbon nanotubes cement composites. Frattura Ed Integrità Strutturale, 5(18), 34-44. https://doi.org/10.3221/igfesis. 18.04

Michálek, M., Kašiarová, M., Michálková, M., \& Galusek, D. (2014). Mechanical and functional properties of $\mathrm{Al} 2 \mathrm{O} 3-$ ZrO2-MWCNTs nanocomposites. Journal of the European Ceramic Society, 34(14), 3329-3337. https://doi. org/10.1016/j.jeurceramsoc.2014.01.039

Mohammed, S. M. A. K., \& Chen, D. L. (2019). Carbon Nanotube-Reinforced Aluminum Matrix Composites. Advanced Engineering Materials, 22(4), 1901176. https://doi.org/10.1002/ $\underline{\text { adem. } 201901176}$

Nazari, A., \& Riahi, S. (2011). Improvement compressive strength of concrete in different curing media by $\mathrm{A} 12 \mathrm{O} 3$ nanoparticles. Materials Science and Engineering: A, 528(3), 1183-1191. https://doi.org/10.1016/j.msea.2010.09.098

Ovid'Ko, I., \& Sheinerman, A. (2010). Ductile vs. brittle behavior of pre-cracked 
nanocrystalline and ultrafine-grained materials. Acta Materialia, 58(16), 5286-5294. htps://doi.org $/ 10.1016 / \mathrm{j}$. actamat.2010.05.058

Salama, E. I., Abbas, A., \& Esawi, A. M. (2017). Preparation and properties of dual-matrix carbon nanotubereinforced aluminum composites. Composites Part A: Applied Science and Manufacturing, 99, 84-93. https:// doi.org/10.1016/j.compositesa.2017.04.002

Sun, J., Gao, L., \& Jin, X. (2005). Reinforcement of alumina matrix with multi-walled carbon nanotubes. Ceramics International, 31(6), 893-896. htps://doi.org/10.1016/j. ceramint.2004.10.002

Xu, B., Smith, P., \& Silva, L. D. (2013). The Bayer digestion behavior of transition alumina formed from roasted gibbsite. International Journal of Mineral Processing, 122, 22-28. https://doi. org/10.1016/j.minpro.2013.04.003 